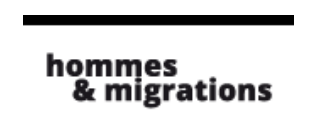

\section{Hommes \& migrations}

Revue française de référence sur les dynamiques

migratoires

1305 | 2014

L'exil chilien en France

\title{
Comment les anciens exilés chiliens contribuent à mettre fin à l'héritage politique de Pinochet
}

\section{Eduardo Valenzuela-Chadwick}

\section{(2)enEdition}

\section{Journals}

\section{Édition électronique}

URL : http://journals.openedition.org/hommesmigrations/2742

DOI : 10.4000/hommesmigrations.2742

ISSN : 2262-3353

\section{Éditeur}

Musée national de l'histoire de l'immigration

\section{Édition imprimée}

Date de publication : 1 janvier 2014

Pagination : 145-148

ISBN : 978-2919-040261

ISSN : $1142-852 X$

\section{Référence électronique}

Eduardo Valenzuela-Chadwick, « Comment les anciens exilés chiliens contribuent à mettre fin à l'héritage politique de Pinochet », Hommes \& migrations [En ligne], 1305 | 2014, mis en ligne le 01 janvier 2017, consulté le 24 avril 2019. URL : http://journals.openedition.org/hommesmigrations/2742 ; DOI : 10.4000/hommesmigrations.2742 


\title{
LES ANCIENS EXILÉS CHILIENS \\ ET LA FIN DE L'HÉRITAGE POLITIQUE DE PINOCHET
}

par EDUARDO VALENZUELA-CHADWICK, sociologue, directeur de Dialogues citoyens, ancien secrétaire général de l'Association d'études et de recherches sur les archives de l’Amérique latine.

\author{
L'arrestation à Londres, en octobre 1998, d'Augusto Pinochet a \\ été pour beaucoup le fait de la mobilisation internationale \\ des anciens exilés chiliens en Europe. C'est le point d'orgue \\ de leur combat mené pendant les années de plomb pour \\ changer les règles du jeu politique imposées par le dictateur. \\ L'impunité de Pinochet et de ses complices civils et militaires \\ après leur départ constituait le signe patent qu'ils étaient restés \\ les maîtres du pouvoir au Chili, verrouillant les institutions \\ et toute possibilité de transformation sociale.
}

Dans sa dernière allocution transmise par Radio Magallanes le 11 septembre 1973, Salvador Allende a légué au peuple chilien un message dans lequel il prédisait - tel un prophète de la démocratie - que les processus historiques ne s'arrêteraient pas, que tôt ou tard se fermerait la parenthèse de la trahison et que les boulevards allaient se rouvrir, par où passerait l'homme libre pour construire la liberté. La parenthèse a duré deux générations et, au Chili ou en exil, des femmes et des hommes ne se sont pas soumis au diktat de la force des usurpateurs et au régime qu'ils voulaient instaurer de façon irréversible. Tout au long du XXe siècle, le Chili a été un pays civique et démocratique, malgré l'héri- tage colonial et une structure sociale archaïque. Les forces armées chiliennes respectaient la Constitution et les lois, à la différence d'autres pays de la région comme l'Argentine, le Paraguay ou la Colombie, qui ont connu une interminable succession d'interventions militaires dans leur vie politique. Les luttes sociales et politiques ont été marquées au Chili par l'émergence d'un mouvement ouvrier et des relais politiques réformistes et révolutionnaires. La jeunesse vivait au diapason des transformations culturelles des années 1960-1970 que connaissaient d'autres pays d'Amérique latine et les États-Unis. Les mouvements étudiants réclamaient déjà une réforme en profondeur des valeurs 


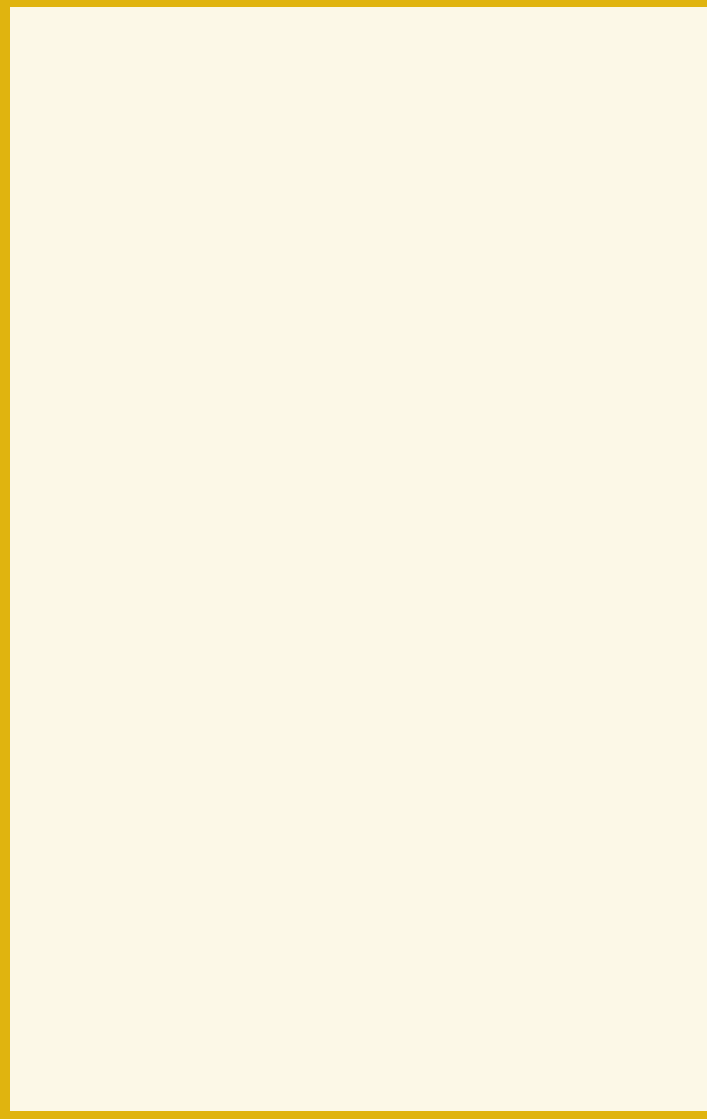

Revue Araucaria de Chile @ D.R.

et du système social. La réforme universitaire au Chili à la fin des années 1960 a été le résultat de ces mouvements étudiants.

\section{La dictature impunie et l'interminable transition vers la démocratie}

Avant le coup d'État de septembre 1973, ces luttes sociales et culturelles avaient permis l'émergence d'une conscience nationale, définie par une demande de justice sociale. Dans ce contexte, la citoyenneté, les droits fondamentaux et la démocratie étaient des valeurs qui émergeaient timidement, en concurrence avec les tendances guévaristes ou castristes de la gauche révolutionnaire. En tout état de cause, les oligarchies nationales ont sacrifié sur l'autel de la guerre froide, et avec la complicité des États-Unis, ce processus historique naissant. Par la suite, elles ont été contraintes de retourner à un semblant de démocratie en feignant de respecter les libertés et les droits fondamentaux aux yeux de la communauté internationale et de l'opinion publique occidentale, pour rendre acceptable la révolution capitaliste imposée sans consensus avec les forces sociales et politiques de la gauche et du centre. La droite a pensé pouvoir tout verrouiller, à commencer par la Constitution, le système électoral et l'organisation sociale et économique, pour empêcher le processus historique interrompu par le coup d'État de reprendre son cours. La clé de voûte du verrouillage de ce système a été l'impunité de Pinochet et de ses complices civils et militaires restés les maîtres du pouvoir au Chili, malgré le départ de la présidence de la République de l'ancien dictateur en 1990. L'arrestation de Pinochet à Londres en 1998 a été un tournant historique dont les Chiliens de l'étranger, pour la plupart des anciens exilés politiques, ont été les acteurs déterminants.

\section{La détention de Pinochet à Londres : la peur change de camp}

La fin de la dictature et l'entrée dans une transition démocratique se sont produites au début des années 1990 grâce à une sortie négociée de la présidence de la République par Pinochet. En par- 
tant, il a pris soin de verrouiller les règles du jeu économique, social et institutionnel et de veiller à maintenir l'impunité pour ses agents civils et militaires. Ce système est resté en place pendant les premiers gouvernements de transition, représentant une coalition qui allait du Parti socialiste à la Démocratie chrétienne, la Concertación de partidos por la democracia, et n'a été véritablement ébranlé qu'avec la détention de Pinochet à Londres. Les exilés chiliens restés en Europe ont joué un rôle capital dans la mobilisation de l'opinion publique européenne et dans le maintien en détention de l'ancien dictateur dans l'attente de son extradition vers l'Espagne, à la demande de la justice espagnole. La justice espagnole et anglaise n'aurait pas pu agir pendant l'année et demie qu'a duré l'affaire sans l'appui d'acteurs capables de représenter les griefs faits à l'ancien dictateur auprès de la justice, de l'opinion publique, des organisations de la société civile et des gouvernements de ces pays. L'Europe et l'Amérique latine se sont passionnées pour cette affaire judiciaire qui questionnait le droit international mais également les transitions vers la démocratie du Cône sud de l'Amérique latine et, par ricochet, celles des anciennes métropoles impériales de la péninsule Ibérique fraîchement sorties elles aussi de régimes dictatoriaux par des pactes d'impunité des anciens caudillos et généraux. C'était la première fois qu'un ancien président de la République était arrêté à l'étranger. L'ordre juridique international a été bouleversé, la souveraineté des États questionnée et mise en concurrence avec le droit international. Tout le monde, juristes, hommes et femmes politiques, gouvernements, intellectuels, avait un avis sur le bien-fondé de cette procédure. Le gouvernement chilien du démocrate-chrétien Eduardo Frei (19942000) s'est opposé à cette arrestation ainsi qu'à l'extradition et au jugement en Espagne de Pinochet : il alléguait une ingérence dans les affaires intérieures du Chili. La propagande déployée par les partisans de l'impunité accusait les anciennes métropoles d'empires déchus d'exercer une jus- tice coloniale. Par de nombreuses manifestations de rue dans toutes les capitales européennes ou face à l'hôpital où l'ancien dictateur était maintenu à Londres, par des articles et reportages dans la presse mondiale, les exilés ont joué un rôle central comme porteurs de la mémoire des crimes commis au Chili et à l'étranger sous Pinochet, et de ce qu'avait été le projet politique avorté de l'Unité populaire du président Allende.

Les victimes de la dictature chilienne se sont tournées vers la justice espagnole lorsque les espoirs suscités par le retour à un régime civil au Chili ont été déçus concernant la possibilité que la justice agisse librement dans les cas de torture, d'assassinats et de disparition de personnes utilisés comme des armes politiques par l'ancien régime. Un rapport officiel (rapport Rettig, 1991) avait proposé dès le retour du régime civil des compensations économiques aux victimes des crimes les plus graves - la disparition de personnes -, en échange du silence des familles et de l'impunité des auteurs de ces disparitions. La loi d'auto-amnistie de la dictature est restée une limite infranchissable. Le premier Président de la transition, Patricio Aylwin, s'était bien accommodé de cette justice, "dans la mesure du possible". Mais cette transition n'était pas à une contradiction près et, au sortir de la dictature, le régime a signé une série d'accords internationaux dans le cadre desquels les procédures ont été présentées en Espagne en 1996 Les exilés chiliens restés en Europe ont joué un rôle capital dans la mobilisation de l'opinion publique européenne et dans le maintien en détention de l'ancien dictateur dans l'attente de son extradition vers l'Espagne, à la demande de la justice espagnole. étaient présentées. De surcroît, comme la dictature avait commis des crimes contre ses opposants à l'étranger, comme l'assassinat du général Carlos Prat à Buenos Aires, celui de l'ancien ministre des Affaires étrangères, Orlando Letelier, à Washington ou l'attentat contre le démocrate-chrétien, Bernardo Leighton à Rome, les victimes ont pu saisir des juridictions étrangères. 
Le juge espagnol Baltazar Garzon a auditionné à Madrid des dizaines de victimes venues porter plainte, et les avocats des droits de l'homme du Chili ont transféré en Espagne leurs dossiers et archives des procès qui n'avaient pu aboutir au Chili malgré la fin de la dictature. En octobre 1998, Pinochet, avec un passeport diplomatique et un statut de sénateur à vie, était en vacances à Londres au moment de son arrestation. C'était sa première sortie hors du Chili après le début de la procédure espagnole. L'ordre de détention et de transfert à Madrid tomba alors qu'il était convalescent d'une opération mineure dans un clinique londonienne. À ce moment-là, dans toute l'Europe, les anciens réseaux des exilés chiliens se sont réactivés. Pendant un an et demi, ils ont appuyé la demande d'extradition à Madrid, alors que le gouvernement chilien de centre gauche négociait avec les autorités anglaises le retour au Chili de l'ancien dictateur. Le verrouillage sans issue qui avait placé la démocratie chilienne dans le modèle néo-libéral a été mis en évidence par le pacte d'impunité que l'opposition à la dictature avait conclu avec l'ancien régime pour accéder au pouvoir et administrer le pays. Cette mise à nu inconfortable pour les anciens opposants et victimes a créé un appel d'air pour réorganiser les mouvements sociaux au Chili et mettre en cause la légitimité de l'héritage de la dictature.

\section{Las grandes alamedas s'ouvrent}

Au travail de mémoire des victimes de la dictature a succédé un travail d'histoire et de justice. Les États-Unis ont ouvert leurs archives sous la présidence de Clinton pour déclassifier et reconnaître officiellement leur intervention dans le coup d'État en 1973. À partir de la détention de l'ancien dictateur à Londres la justice au Chili a avancé substantiellement. Un rapport sur la torture (Rapport Valech, 2004) et des dizaines de procès ont prouvé la responsabilité des agents de la dictature dans la disparition, l'assassinat et la torture de milliers de Chiliens. Les principaux tortionnaires sont aujourd'hui en prison. Même si l'architecture du modèle hérité de la dictature reste en place, celleci a été ébranlée par la fin de l'impunité.Des mouvements sociaux ont vu le jour alors qu'ils avaient été démobilisés à la fin de la dictature, pendant les années 1990. La coalition d'opposition à la dictature a dû incorporer cette demande de transformation dans son programme politique.

Depuis le début des années 2000, les mouvements étudiants qui se sont succédé en 2001, en 2006 et en 2011 connaissent une approbation majoritaire avec $80 \%$ de la population qui appuient leurs revendications. Le mouvement de 2001 réclamait un "pass" de transport pour tous les étudiants et lycéens, celui de 2006, une réforme du statut de l'Éducation publique, celle-ci avait été privatisée et placée sous la responsabilité des municipalités, créant un système très inégalitaire entre les communes riches et les communes pauvres, entre l'éducation privée et publique. Le mouvement étudiant de 2011 porte des revendications de réformes politiques, il réclame une éducation publique et gratuite pour tous, une réforme fiscale et un changement de la Constitution héritée de Pinochet. Ces demandes ont pesé récemment fortement sur l'agenda politique et sur les élections présidentielle et législative de Michèle Bachelet en 2013.

Les Chiliens restés en exil ont favorisé le changement des règles du jeu politique héritées de la dictature. Le système, qui perdurait et qui verrouillait les possibilités de transformations sociales et politiques de fond, a été ébranlé. La jeunesse chilienne s'est emparée de l'espace de liberté qui en a résulté. Les gardiens du temple pinochetiste ont bien compris le rôle joué par les Chiliens de l'étranger en leur refusant, depuis le retour à un régime civil, l'exercice du droit de vote. Allende n'est pas mort en vain, les Chiliens de l'exil l'ont porté en étendard, ils en ont payé le prix avec fierté. À eux revient cet hommage : les boulevards, las grandes alamedas, s'ouvrent enfin de nouveau. 